Covered in: Web of Sciences (WOS); EBSCO; ERIH+; Google Scholar; Index Copernicus; Ideas RePeC; Econpapers; Socionet; CEEOL; Ulrich ProQuest; Cabell, Journalseek; Scipio; Philpapers; SHERPA/RoMEO repositories; KVK; WorldCat; CrossRef; CrossCheck

2018, Volume 10, Issue 4, pages: 265-281 | doi: https://doi.org/10.18662/rrem/87

\section{School Career and Inclusive School between Breaks and Continuities in Children and Adolescents Suffering from a Disabling Disease}

\section{Patrice BOURDON ${ }^{1}$}

${ }^{1} \mathrm{Ph} . \mathrm{D}$. in Educational Sciences, University of Nantes - Ecole Supérieure du Professorat et de l'Education (ESPE), Centre de recherche en éducation de Nantes - CREN EA 2661, France, patrice.bourdon@univ-nantes

\begin{abstract}
The schooling of students with health problems (cancer, disabling illness, accidents, etc.) is severely disrupted both in terms of disruptions to schooling and in terms of learning challenges with uncertain time horizons. The schooling systems dedicated to this public, sometimes in a situation of disability, are articulated and complement each other so as to maintain an inclusive school career with and in spite of situations of rupture. The link between school stakeholders, parents and hospital professionals is essential and is based either on existing institutional frameworks (hospital education systems, home schooling, regulatory texts, specific financial resources, distance education, etc.) or on resources created according to individual situations and emerging needs in the context.

So the central question of this communication could be declined as follows: to what extent does the complementarity of actors and special teaching arrangements allow inclusive schooling when breaks are strongly present and the risks of exclusion are at the heart of the issues?
\end{abstract}

Keywords: school career; children with health problems; inclusive school.

How to cite: Bourdon, P. (2018). School Career and Inclusive School between Breaks and Continuities in Children and Adolescents Suffering from a Disabling Disease. Revista Romaneasca pentru Educatie Multidimensionala, 10(4), 265-281. https://doi.org/10.18662/ $\mathrm{rrem} / 87$ 


\section{Introduction}

A number of research studies have shown that a fairly fragmented organisation prevailed in the schooling of pupils with special educational needs: related to health problems affecting them, those with disabilities or those with learning difficulties. Godefroy Lansade shows that the multiplicity of care, whether pedagogical or rehabilitative, can prove to be problematic in terms of continuity and emphasises. For example, the alternation between inclusion class and Ulis ${ }^{1}$, specific to each pupil, is organised between grouping times within the Ulis and inclusion times in the class corresponding to their professional "choice". The timetable is in fact divided between workshop time, associated knowledge (theoretical courses linked to professional practice), general teaching and grouping time within the Ulis. In addition, rehabilitation and/or therapentic care is provided during school hours (Lansade, 2015: 101). Marie Toullec-Théry, also shows that the aids provided by the $\mathrm{AVS}^{2}$ (AESH today) in class often takes the form of the implementation of a system where the teacher manages the "ordinary" pupils while the AESH takes care more particularly of the disabled pupil producing a pedago-didactic exclusion from the inside. In fact, she points out, teachers have a great deal of confidence in AVS and, as a result, delegate a large part of their responsibilities to them. Moreover, she underlines (Toullec-Thery and Pineau, 2015) the way in which didactic time is inequitably broken down between ordinary pupils and those with disabilities because in [her] conception of teaching, the teacher is faced with a dilemma: in order for teaching time to advance rapidly (and respond to his concern to honour the whole program), he would have to question the chronogenic, "good" and "compliant" pupils (SchubauerLeoni, 1988), who naturally fit into the contract, while inserting (nevertheless) the others, including pupils with disabilities, who are nevertheless poor in "capital of adequacy" (Sensevy, 1998, as cited in Toullec-Théry and Pineau, 2015). In co-teaching contexts where two teachers work together in a classroom, it is common to see the sharing of the group, one taking the most difficult ones at times when the other takes care of the rest of the class. As it is not always the same students who make up the group, nor the same subjects that are taught in this way, then the transitions of situation and learning context are numerous and some students may have difficulty perceiving the continuity of learning and the aids provided.

\footnotetext{
${ }^{1}$ Unité localisée pour l'inclusion scolaire : Localized unit for school inclusion - 1st and 2nd grades - support system for school inclusion reserved for pupils with disabilities attending regular classes

${ }^{2}$ School life assistant - Accompanying disabled pupils
} 
In this article, we wish to question the school career of students suffering from a serious illness and "prevented" from attending an ordinary school because subject to the vagaries of care, the evolution of the health disorder whether it is an illness or an accident. The aim is to focus in particular on the actual time at School and to understand the transitions made of ruptures and continuities. Those who work in the schooling of pupils with special educational needs because, more than any other pupil, the latter generally experience a schooling that is rather disjointed in two ways: the time of medical or re-educational care and support is essential, but as soon as possible these pupils return to school learning wherever they go to confront it.

\section{Context and problem of schooling for sick children}

In France today, more than 13000 children and adolescents benefit each year from education at their bedside, in a hospital's classroom, in a rehabilitation centre, with an educational assistance system at home (APAD) or with the National Centre for Distance Learning (Cned). They then move between these different periods of schooling according to their state of health. The partners who operate in this specific schooling do not always coordinate themselves, leaving it to the student to find the meaning of this fragmented path.

We have shown in various articles that the way in which the pupils constructed themselves with and in the School, was partly linked to the way in which the course unfolded (Bourdon, 2016; Bourdon and Toullec-Théry, 2017). To us, it seems necessary to address the question of diversity of pathways in relation to the multiplicity of learning forms and varied contexts of schooling. Although pupils are usually confronted with school content essentially in a classroom context at school, and they are evaluated in and on these school forms. It must be considered that with regard to the specific situation of pupils suffering from a disease, School takes on various colours and breaks down into multiple forms and procedures to allow it's content accessibility over fluctuating periods of time. This is how sick or injured children will use different spaces to learn. On several occasions, we have mentioned in our work the different places, or "environments" as Wallon (Wallon, 1959) would have said, which can, outside the school curriculum, allow new acquisitions (the medical practice, rehabilitation, other pupils, hospital staff...). It is also necessary to question the effects of nomadism on these pupils, due to a scattered learning patterns between home schooling (alone or with a teacher), school in hospital (in class or in their room) or in 
their usual school, without forgetting those who follow an education by correspondence at the Cned. (Bourdon and Toubert-Duffort, 2017).

Marie Hélène Jacques (2016) is interested in transitions in school's context defined, in her simplest understanding, as an interaction between an individual and a context with the hazards that this entails for students with the greatest difficulties or disabilities insofar as these transitions are not anticipated, as for most students. They are subject to a number of contingencies related to "cumulative micro-situations[which] can then aggregate to produce strong irreversibilities", that is, situations proposed to meet students' needs will sometimes go against the expected effect. In fact a schooling fragmented in several consecutive spaces in sick or injured children can produce an irreversibility to choose its orientation. For example, some students no longer have marks validated by the institution and cannot take part in the orientations on school files. Without forgetting the multiple individual support, the various re-orientations during schooling, the "inclusions" in such or such class, it is indeed an accumulation of various organizations with more or less long terms which characterize the schooling of this public (Bessin, Bidart, and Grossetti, 2009).

We also know that there are many organizations with the evolution of digital systems to maintain the link according to the context of schooling. Thus technological evolutions and distance learning practices allow multiple innovations with the Digital Workspaces (DWSP) developed by the rectorates. So students who are far from school (especially middle and high school students) have access, from wherever they are, to a workspace on which their regular teachers can drop exercises, lessons or corrections made to the interactive whiteboard (TBI), make use of telepresence robots. We also know that current social networking practices allow us to share not only life events, but also activity content, whether they are academic or more personal (Bourdon \& ToubertDuffort, 2017).

The new possibilities offered, in response to the situations of these pupils, require education actors to focus on needs, rather than on disorders, in order to think of accessibility to school and not the technological compensation of a difficulty. That is to say that in taking into account their specific needs, pupils suffering from serious health problems have atypical school careers made up of multiple orientations, breaks, part-time schooling, stays in care and rehabilitation centres, which by nature leads them to

\footnotetext{
${ }^{3}$ Here voluntarily used as often in teachers to indicate that a student "goes" a few mornings or hours a week in another regular class and leaves the specialized device.
} 
experience many transitions, sometimes unexpected, other times anticipated. During the time of the micro context of the classroom in the hospital or school of origin, students are often led to move from one environment to another, from one teacher to another, sometimes even different teaching materials according to school spaces.

It is therefore a time to question-in a central way the effects of transitions linked to the schooling of sick or injured children and adolescents, more broadly those with special educational needs, effects on pathways and on ways of being a pupil. Generally atypical, made up of specific orientations linked to the situation of the person and its needs (the evolution of motor disorders at certain periods of life or the deterioration of the state of health, for example), the schooling of pupils suffering from health disorders is also inscribed in evolving socio-historical contexts: indeed, the total absence of schooling during convalescence in many countries, in France before the last half of the twentieth century was of no concern to anyone.

\section{From integration to inclusion: the emergence of the notion of pathways made of transitions}

Inclusive schooling, even if it is at the heart of current international policies, generally supported by national regulatory texts, is a paradigm whose implementation implies new challenges since, beyond modifying practices, it requires thinking of School, in its entirety, as accessible to everyone, well beyond situations of disability. As Serge Ramel and Raymond Vienneau point out, the legal framework has contributed to the formation of our representations of inclusive education by focusing more on children with disabilities or in serious difficulty (Prud'homme, Duchesnes, Bonvin, and Vienneau, 2016: 25). This is why inclusive education must therefore be part of a perspective of education for all, without being limited to one category of children (Prud'homme et al.: 33). However, it is a question here of thinking not according to the category of child but according to the different context made unavoidable for the necessity of care in an extraordinary environment as opposed to the regular one of the usual living environment. It is complex insofar as the substitution of the word "integration" by "inclusion" in the early 2000s in the wake of the Salamanca declaration in 1994, may suggest that it is a scale of value in terms of additional schooling time in ordinary classrooms. It is as the authors point out, on the basis of this declaration, that this second wave of institutional injunctions allows us to note that the speech of international bodies now focuses on equal access and right to an education offered within the same public education system 
(Prud'homme et al., 2016) Pupils suffering from health disorders have largely benefited from this international impetus since numerous regulatory texts and schooling schemes opened up in France during the 1990s/2000.

\section{Inclusion: between organization and process}

There is a confusion between a schooling procedure, which teachers often call "inclusion": it is included from 9 a.m. to 12 p.m. in grade 6; and a long and complex process of citizen participation and life in society, in which school inclusion participates. So, to confront the question of inclusive schooling with that of schooling pathways seems relevant to us to look at from a historical point of view. Indeed, this concept appeared quite recently in the language of the professionals of this application scope but also in the legislative texts concerning the handicap. The work done of Roca (1992) and Simon (1988) shows that when children and adolescents with disabilities are placed in specialized institutions, their only course was generally limited to entering and leaving after a fairly long period, often in boarding schools with internal schooling at best. The same was true for those placed in sanatoriums until the 1960s: long stays away from home for treatment were common practice. It was then a continuous journey, certainly outside the regular schooling of all, but which has as points of reference, the entry into the world of education: continuity without external transitions. We can then speak of a specialized career path which is also part of transitions for some since generally after a beginning of schooling in an ordinary environment, the orientation in a specialized establishment proceeds from a more or less chosen change. At this stage, it seems useful to us to return to the question of transitions which, depending on how they are achieved, will introduce breaks or continuities in the process.

In any case, it can be identified with a transition by referring to these two approaches, that of Colin Murray Parkes (1971) which is defined by "major changes in living space, which have lasting effects, that occurs in a relatively short space of time and decisively affect the representation of the world", and Nancy Schlossberg's (2005) which specifies that this corresponds to "any event or lack of an expected event which has the consequence of transforming relationships, routines, beliefs and roles. ». If we stick to these definitions, we must therefore understand the patterns of schooling that contribute to building a more or less coherent school career, chosen, suffered, anticipated or not. In fact, the stages that will generate differences in the school career are highly differentiating according to school populations, even if the levels are marked out by common markers for all students:

- age of entry into primary school 
- age of transition to college or high school

- advanced education

- enrolment in a class whatever the level of schooling...

When an unexpected event occurs, there is usually a major change in schooling. It turns out that sick or injured children and adolescents, as we have said, often have to live (undergo) multiple changes in their school career. The various school orientations they experience during this period of care sometimes turn out to be disjointed, little followed, subject to multiple hazards, including even in the course of their school days. Trying to understand the pathway and transitions in the school context can reveal, in fact, facilitators and barriers to greater inclusive schooling.

\section{Be vigilant about transition times}

Marie Hélène Jacques (2016) points out that transitions in the school context are of several kinds. They can be anticipated, unexpected, chosen, suffered, experienced or not, depending on the goal markers identified by the students and their families.

We can indeed identify structural transitions linked to the transition from one class to another, from one level to another, from one orientation to another. All this being generally anticipated and in the natural order of the evolution of schooling linked on the one hand to age, on the other hand to school results. There are, however, transitions of orientation within this framework. [that] require a decision by students and their families[that] are subject to an institutional injunction (to a stream, options, an institution) (Jacques, 2016). There are also, and this is often the case with disabled, sick or injured pupils, transitions suffered as a result of hazards along the way; either because they run counter to ordinary pathways (specialised structures linked to disability), or because they are the result of an institutional decision (refusal to direct towards such courses because of an insufficient level of education, lack of space), or as regards the population which occupies us here, by the advent of an illness or accident which by nature is unexpected.

We can also identify ruptures that occur in the daily life of schooling when students live various daily organizations:

- the time of the care in room or in cabinet

- the time of re-education

- time for rest, convalescence

- the different school or educational times

- time for home lessons with dedicated teachers

- the time for a partial return to class when health improves... 
The process that develops over the course of the upheavals linked to illness or accident leads us to question the transitions between the different learning spaces: How does the school institution shapes the orientations during the stages that mark out the schooling of these pupils? Which orientation committees, which statutory bodies act on the course when this is not the case for "ordinary" pupils? How are "out-of-school" knowledge and grades taken into account?

In this case, it is potentially possible to question the extent to which these stages divide the schooling path, especially for those that fall into the category of transitions suffered, since very often it is confrontation with regular school that leads to an awareness and a demand for recognition of the disability or a health disorder that highlights this impossibility of regularly pursuing school learning. Moreover, parents are not always in favour or have difficulty accepting these reorientations, these contingencies.

\section{The Fragmentation of the Pathway: a Specificity of Pupils with Special Educational Needs}

"The notion of an inclusive school is based primarily on an ethical principle: the right of every child, whoever he or she may be, to attend regular school. It opposes the exclusion or exclusion of certain categories of children, depending on their characteristics. It also differs from integration in that it does not involve accepting or reintegrating into school children who were initially considered to need separate education because of differences or particularities.... Inclusive education, on the contrary, is a radical position requiring schools to transform themselves into school communities where all learners are welcomed on the basis of equal rights." (Plaisance, Belmont, Verillon, and Schneider, 2007).

One of the paradoxes of the schooling of students with disabilities or health problems, then, would be linked to the taking into account of special educational needs which produces multiple adaptations, microsituations "pedago-didactic", multiple interventions of different teachers, or even different trades in the same learning space: the School. Anne Gombert specifies These adaptations, developed specifically for a student, do lead to the implementation of individualization, but they can take on a more or less individualizing character depending on the degree of distance between the student's learning objectives and those of the class group. Thus, succeeding in no longer contrasting differentiation/ individualization/ adaptation, but rather considering the continuum that links them, leads to identifying the complexity of the conception of the adaptation of teaching in the ordinary classroom context (Gombert, Bernat, and Vernay, 2017).

Corinne Mérini and Serge Thomazet showed how most of these students navigated between multiple aids or support devices to meet what 
are identified as special educational needs and that it required great caution to avoid the discomfort of fragmentation and more co-organizations, collaborations between professionals. Thus they specify the implementation of projects, or pathways if one is content to change the terms, can lead to think of collective work as juxtapositive or better as articulated where in fact it should be reticulated. Working together is, from our point of view, co-acting and co-deciding in a professional space anchored in networks. To give just one example, we can start from the situation, which could not be more common, of a young person who, in addition to school, needs speech therapy, psychological help and educational support. These multiple medical, educational and school needs require both more school than other children, but also more care, more support. Traditionally, multidisciplinary meetings are the occasion for each professional to make renunciations in front of days that are not extensible. In the end, these young people who need more... have less, because of the juxtaposition of the activities of different professionals (Mérini and Thomazet, 2014). Re-educational or care services are part of the timetable of pupils who generally already benefit from a course organisation made up of multiple participants (specific teachers according to the time and place of schooling, school life assistants, teachers of origin, etc.). What governs the organisation of these external aids, however, is not the timetable of the pupils but rather that of the professionals who arrive less than that for their activity whatever it may be. The continuity of learning, the link between the different teaching bodies (a day in hospital for example) are interrupted by one-off care during the day, during the week by different care professionals, rehabilitation, educational workshops, "virtual" professionals sometimes through digital networks.

\section{What about school careers and transitions for sick or injured children?}

In order to better illustrate this reflection, I wanted to build on the data collected during my previous research in the field. Thus a knowledge assessment survey was conducted among 70 pupils followed by a home schooling scheme, another among 75 teachers accompanying very seriously ill pupils (Bourdon and Toullec-Thery, 2017), and finally it is completed by an analysis of existing schemes to enrol these pupils. For the first situation, the approach undertaken was therefore to collect a written account on what drives the subject in learning. It was a question of bringing to light specificities, or not, in the relationship to knowledge for sick or injured children. The knowledge evoked despite the very different nature of some, others and the environments in which they are acquired, are sometimes expressed under the same status as others met in the school setting. Indeed what to say of "learning suffering, to fight, solidarity" in echo to "learning to read, 
English...". These are obviously categories that not only do not have the same "market" value at the school level but also mobilize the emotional level in other ways. The following are the most significant categories ${ }^{4}$ that may have specific motives for learning related to the illness or accident.

\section{Evolution of knowledge objects and dynamics according to teachers}

Among the teachers surveyed, many point out elements of context that will affect the teacher/pupil relationship and gradually modify both the content of knowledge and the object of the mission, "the child's suffering was such that she no longer wished to show me her face altered by the care. Too much fatigue too, despite the comfort of my presence". Over the course of the various interviews, we show that teachers will move from a teaching mission to one of accompaniment, that is, from the epistemic field to the social field (Bourdon and Toullec-Théry, 2017). The continuation of the action is expressed through a lexicon oriented towards "comfort", "being in school like others", "sharing", "the right to education", or the fact that "sick children need to keep in touch with the school world". One school teacher said: "I asked myself, for me, he was a student like any other. This other high school mathematics teacher, who works from home, also points out that it is useful to "continue all the same[to] contribute to a "normal" environment that creates a social bond.

While these are essential elements to be taken into account in order to respect the child's state of health and well-being, it is interesting to note that, here, the comments put forward to justify the continuity or not of the lessons are related to the consequences of the illness, while others speak of cognitive rupture, of difficulties of concentration.

A senior education adviser (CPE) at the high school still said: "It was a question of whether it was wise to let the pupil come to class and risk an even greater weakening of the body while the treatment greatly weakened the pupil, who could therefore only be transported in a wheelchair". When it comes to questioning the continuity of the courses and evoking the potential stoppage, a physical science teacher, intervening at home, reports "too many physical constraints". The teachers' writings are numerous showing that the limits of the intervention are constrained by the physical dimension of the suffering and painful body, by its transformation. These elements therefore guide their pedagogical choices.

Among hospital professors, the institutional framework, the retention of schooling and their specialization guide the question of continuity differently. They are more experienced with the suffering and

\footnotetext{
${ }^{4}$ Either because they are recurrent in speeches, or very specific or singular given the audience solicited.
} 
physical changes of their students, and none of them even go so far as to say that "in fact, we don't ask the question, it seems so obvious that young people are demanding, that we can't refuse to provide them with this service". We have more readily found an epistemic dimension in the comments of these teachers, with the question of knowledge at the centre of their arguments of rupture or continuity of the learning path (Bourdon and Toullec-Thery, 2017).

\section{Education Configurations and Activity Environments}

By modelling the school and social environment of students with health problems, we can see that the number of functional and local environments (in the Wallon sense) is quite large.

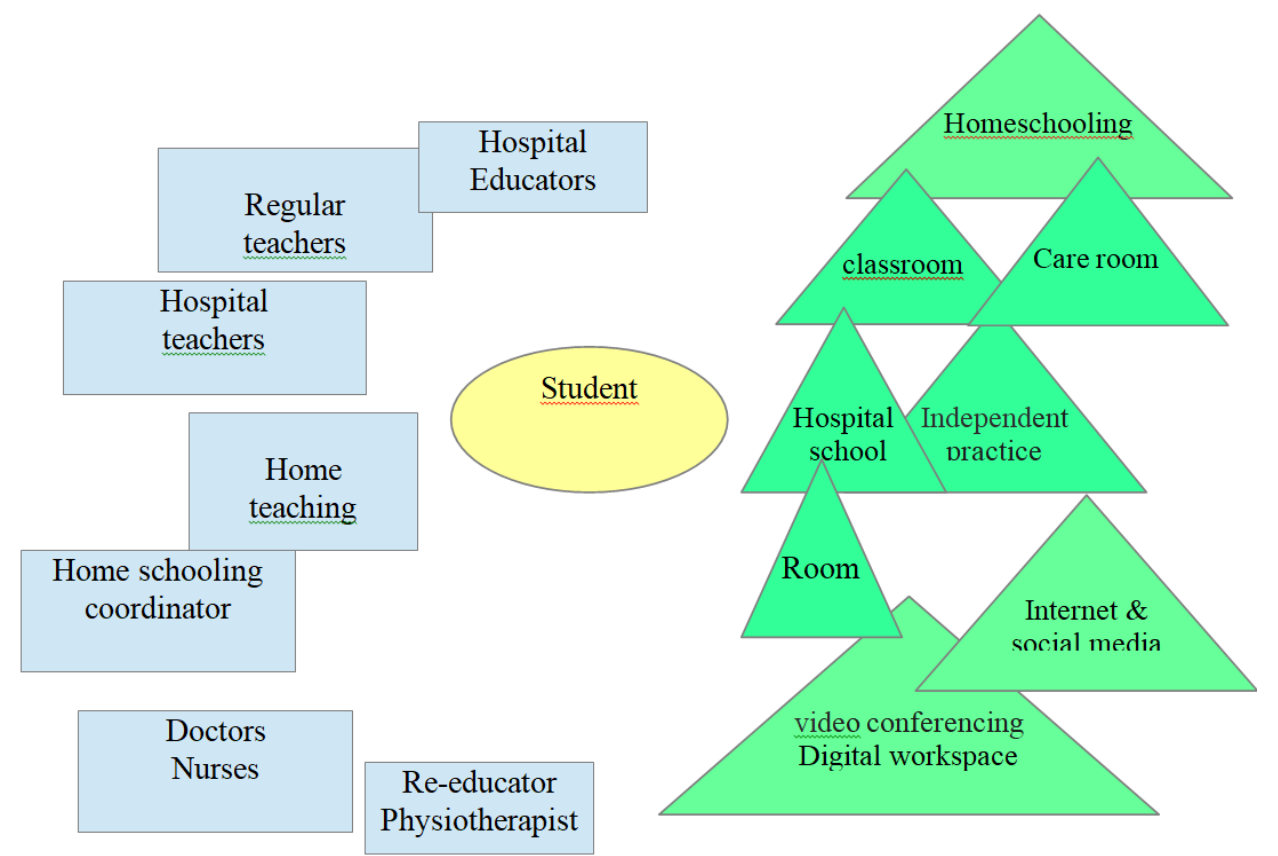

It can be seen that more than other students, those benefiting from schooling during the period of care or rehabilitation, are subject to multiple transitions, multiple stakeholders of different nature. They navigate between the different learning spaces, the different people who are sources of knowledge, the different forms of schooling or non-school, the multiple opportunities to learn about what is happening to them and what is at stake in life at that time. 


\section{Breakdowns and Continuities in Learning from the Students' Perspective}

To understand what these students tell us, we have classified the answers according to two themes:

- Variations according to the length of convalescence or care (hospitalization and home included)

- Variations according to pathologies: chronic disease / cancer and leukaemia / accident - trauma - surgery

\section{What will be the consequences depending on the duration of the absence.}

For pupils absent for a short period ( $<1$ month), the knowledge indicated in the assessments is quite generic (learning things, new things, lots of things...) whatever the pupil's school level. It is also stated a need to continue, continue. For them, the episode of absence from school and the often benign nature of the disease (surgery, fracture, flu, etc.) has little or no effect on their motivation to learn or on their relationship with knowledge. Students then wish to find the best learning conditions and continue their usual schooling. Thus continuity is the driving force behind schooling.

For pathologies requiring an absence of one month or more, three main categories of answers are revealed:

* Investing school knowledge for training purposes:

Some pupils express the need to re-appropriate the school institution, its mechanisms, its organisation and evoke more frequently subjects or learning contents to invest in order to catch up and enrol again in ordinary schooling. They can focus on a diploma logic in order to have a profession. Some professions to which they would like to have access are very closely linked to the medical field: doctor, biologist, medical nurse... So there is a break here that triggers a process of continuity of the journey.

* Investing the knowledge of life and social experience:

Students suffering from serious illnesses leading to significant suffering or a reserved prognosis for recovery (cancer, leukaemia, cystic fibrosis, etc.) say that they have above all learned life, to build their life "because it is short", to succeed in their life, to live like others, etc. They are more willing to focus on a long period of time (life) or on an essential process (living). Knowledge is therefore not evoked precisely in relation to School or to what is expected of a student. One can make the hypothesis of a significant mobilization on life experience during this period. This does not rule out a substantial 
investment in home-based educational assistance as a way of dealing with the disease and projecting oneself into the future.

* Appropriating knowledge to the test of disease:

Another type of response is oriented towards learning about suffering, the ability to fight, loneliness or solidarity. It is the knowledge of experience that is built up in the test of disease. We can note that this knowledge is of the human order, in relation to humanitude while being very much in connection with the environment or the experience of the medical world.

There is no specific difference according to the age or level of education of the sick or injured child, but more directly related to the length of his convalescence or the severity of the pathology. It seems that illness or accident, which requires more than several weeks of care, then leads to a questioning and an emphasis on certain knowledge less focused on the School. This strong break in the school career is part of a transition towards a longer period of time that characterizes the learning path.

\section{What will be the consequences depending on the disease?}

The second path of analysis is placed in the types of pathologies. For students with a chronic illness, academic knowledge is clearly exposed, whether basic (reading, writing, counting), generic (things, many...) or disciplinary (science, physics, modern languages...). We also notice that some knowledge is correlated with other environments, notably medical or meeting other people sick or not. However, even if they summon knowledge acquired in other environments according to their medical experiences, the discourse is centred on the School. They give sufficient explanations to show that they are familiar with the school system and its logics (school transition, difficulty level in secondary school, average results, etc.).

It is difficult to state with certainty the causes of this diversity of categories of knowledge for this population. However, it can be assumed that these diseases present from birth (even if they occur later) are known, appropriate and tamed by the sick child. The construction of time perspectives is different than during a sudden illness or accident.

For children or adolescents with cancer or leukaemia, the question of temporality is very recurrent. It is associated with duration, whether in breaks in school rhythm or in the continuity of life. Verbs that mark a temporality (build, catch up, continue...) are present. There is no knowledge explicitly mentioned in a broad way as in the previous category of pupils. We think they link this directly to the announcement of the disease in 
terms of dismption, trauma. This sudden revelation of a serious illness causes a temporal disruption in life. Existential and finite questions then arise. Continuity is to be (re)built. There is probably a greater mobilization of oneself over time than on academic knowledge.

In the third category, "traumatic accidents - surgeries", we observe the presence of both the question of temporality and a logic centred on the School. An accident or surgery is generally unpredictable and causes $a$ temporal rupture, a momentary immobilization. Students in this category say they want to find, continue, and move up in the class... which is part of a timerelated process. For those whose immobilization is longer ( $>3$ months), relationships with others, community life is frequently evoked as in the category of students with cancer or leukemia; this being related to the length of convalescence more than to the type of pathology. This social life is exposed in terms of knowledge: learning to live together, getting to know oneself better. In this type of pathology, rehabilitation can be long, but the accident does not necessarily lead to a compromised vital prognosis. This is why we find associated with this social knowledge, knowledge of reinvestment of the School in order to find the school quickly. It is only in this category, moreover, that we note the presence of a discourse demanding the number of hours of classes given by home schooling services, it is a pity that there were only two subjects... I think that any hospitalisation requires a school break and the child must benefit from these aids... This logic is of course part of the nature of the traumatic episode which can (or must) be a parenthesis in life. Focusing on school dynamics then makes it possible to project oneself into a future which in these conditions, given the pathology, can be envisaged.

The questions that arise from the ordeal of the illness or accident, depending on the seriousness and the moment at which it occurs, can lead to mobilizations on the specific learning for the student. As we have shown, some students are part of a relationship with knowledge and learning, a mobilization, an interest in this or that type of knowledge depending on the repercussions it has for them. These are processes of self-building "influenced" by the history of the subject, by the event experienced. We know, because teachers say so or because school results show it, that some students after an illness or accident experience mobilize differently at the School. The stakes of learning it take a particular color, essential for them. 


\section{Conclusion}

This article has allowed us to show how the school careers of sick or injured students are subject to multiple hazards, changes and fragmented contexts. These pupils benefit more than others from taking into account their special educational needs, but this also has the effect of producing adjustments in both schooling and medical, rehabilitation or psychological care. On the strength of these situations and contexts, it is therefore essential to think about transitions in the school context, both in terms of pedago-didactic continuity, as well as in terms of the support provided by multiple actors. It is most probably at this price that they will be able to benefit from a schooling which is based on a built, anticipated and not suffered course. Learning, the experiences of continuity despite break-ups, the feeling of belonging to the community of peers, the possibilities of projecting oneself into a school and/or professional future, and the progressive awareness of the new possibilities as well as the constituent shortcomings of any subject, are thus, for the young patient and his parents, the main challenges to overcome the ordeal of the illness or serious injury. The continuation of the schooling path, beyond school learning, then seems to us essential to allow the construction of the subject whatever his situation. It is at this level that we can question the inclusive process because we measure through the example of this specific population that the continuity of the pathways, in spite of the epistemic reorganizations that act in the learners, makes it possible to maintain the link with the School whatever the situation and the needs of the subject, it is then fundamental to maintain schooling that gives access to confrontation with knowledge and with others.

\section{Acknowledgment}

The article has been presented at The XIX ${ }^{\text {th }}$ Congress of the AMSE-AMCEWEAR, 4 - 7 June 2018, Stefan cel Mare University of Suceava, Romania.

\section{References}

Bessin, M., Bidart, C., \& Grossetti, M. (Coords.). (2009). Bifurcations: les sciences sociales face aux ruptures et à l'évènement [Bifurcations: The social sciences face breaks and the event]. Paris, France: La Découverte

Bourdon, P. (2016). Parcours scolaire et scolarisation inclusive chez les élèves avec un trouble moteur [School pathway and inclusive schooling for students 
School Career and Inclusive School between Breaks and Continuities in ... Patrice BOURDON

with a motor disorder]. In M. H. Jacques (Ed.), Transitions en contexte scolaire (pp. 379-390). Rennes, France: PUR.

Bourdon, P., \& Toubert-Tuffort, D. M. (2017). Scolariser les enfants malades ou accidentés: Evolutions, enjeux et perspectives [Schooling sick or injured children: Evolutions, issues and perspectives]. La nouvelle revue de l'adaptation et de la scolarisation, 79-80, 215-226. Suresnes, France: l'INSHEA.

Bourdon, P., \& Toullec-Théry, M. (2017). La scolarisation des enfants et adolescents avec une maladie grave: que disent de leurs pratiques les enseignants confrontés à ces élèves? [Schooling of children and adolescents with serious illness: What do teachers say about their practices?] La nowvelle revue de l'adaptation et de la scolarisation, 79-80, 7-28. Suresnes, France: l'INSHEA.

Gombert, A., Bernat, V., \& Vernay, F. (2017). Processus d'adaptation de l'enseignement en contexte inclusif : étude de cas pour un élève avec autism [Process of adapting teaching in an inclusive context: a case study for a student with autism]. Carrefours de l'éducation, 1(43), 11-25. doi:10.3917/cdle.043.0011

Jacques, M. H. (2016). Transitions en contexte scolaire [Transitions in school context]. Rennes, France: PUR.

Lansade, G. (2015). Entre classe d'inclusion et Unités pédagogiques pour l'inclusion scolaire en lycée professionnel: suivis ethnographiques d'une scolarisation adaptée [Between inclusion class and educational units for inclusive education in vocational high school: ethnographic follow-up of adapted schooling]. Recherche en éducation. 23, 95-104.

Mérini, C., \& Thomazet, S. (2016). Faciliter la coopération entre les différents acteurs de l'école inclusive [Facilitate cooperation between the different actors of the inclusive school]. Parcours de vie et accompagnement, 1(2), 25-31.

Parkès, C. M. (1971). Psycho-social transitions: A field for study. Social Sciences and Medicine, 5(2), 101-115. doi:10.1016/0037-7856(71)90091-6

Plaisance, E., Belmont, B., Verillon, A., \& Schneider, C. (2007). Intégration ou inclusion? Éléments pour contribuer au débat [Integration or inclusion? Elements to contribute to the debate.]. La nowvelle revue de l'adaptation et de la scolarisation, 37, 159-164. Suresnes, France: l'INSHEA.

Prud'homme, L., Duchesnes, H., Bonvin, P., \& Vienneau, R. (Eds.). (2016). L'inclusion scolaire: ses fondements, ses acteurs et ses pratiques [Inclusive education: Its foundations, actors and Practices]. Bruxelles, Belgium: De Boeck Supérieur.

Roca, J. (1992). De la ségrégation à l'intégration: l'éducation des enfants inadaptés de 1909 à 1975 [From segregation to integration: the education of unsuitable children from 1909 to 1975]. Paris, France: PUF. 
Schubauer-Leoni, M. L. (1988). Le contrat didactique dans une approche psychosociale des situations didactiques [The didactical contract in a psychosocial approach to didactical situations]. Interactions didactiques, 8, 6375.

Schlossberg, N. K. (2005). Aider les consultants à faire face aux transitions: le cas particulier des non-évènements [Helping consultants deal with transitions: the special case of non-events]. L'Orientation scolaire et professionnelle, 34, 85101

Simon, J. (1988). L'intégration scolaire des enfants handicapes [School integration of children with disabilities]. Paris, France: PUF.

Toullec-Théry, M., \& Pineau, V. (2015). Inclusion en cours d'histoire dans une classe de $5 e$ de college : une étude de cas [Inclusion in History in a fifth grade class in France: A case study]. Éducation et didactique, 9(1), 33-55.

Wallon, H. (1959). Les milieux, les groupes et la psychogenese de l'enfant [The backgrounds, groups and psychogenesis of the child]. Enfance, 12(3-4), 287296. 